\title{
The Role of Multi-Sensory Experience Toward Perceived Medical Service Quality: A Research at Vietnam Public Hospital
}

\author{
Huyen Pham Thi ${ }^{*}$ Nhi Tran Que Long La Gia Doan Ha My Vu Tien Duc \\ Marketing Faculty, National Economics University, 207 Giai Phong Street, Hai Ba Trung District, Hanoi \\ 100000, Vietnam
}

\begin{abstract}
The theory of Sensory Marketing has been developed as a special approach to help managers understand customers through creating multi-sensory experiences. In medical services, a patient's multi-sensory experience with a medical facility will shape each customer's different perception of service quality. The article evaluates the role of multi-sensory experience in customers' perceived service quality at public hospitals in Vietnam. Research results have shown that tactile, olfactory, visual and taste stimuli have a significant influence on the perceived service quality of customers when experiencing medical services. Besides, the authors also detected that customer's expectation and satisfaction have a proportional relationship. Discussions and recommendations on the application of sensory marketing to improve people's perception of the medical service quality have been proposed to enhance the brand image of Vietnam's public hospitals as well as to ensure the interests of the customer during the use of the service.
\end{abstract}

Keywords: sensory marketing, perceived service quality, medical service, public hospital.

DOI: $10.7176 / \mathrm{JMCR} / 83-02$

Publication date: December $31^{\text {st }} 2021$

\section{Introduction}

Senses can be considered as "terminal devices", absorbing information signals to humans. On that basis, people will process information collected from the senses, and create feelings and opinions. This is also the basis for people to make decisions. Through the senses, individuals gradually become conscious and aware of products and brands (Hultén, Broweus, and Dijk, 2009). Therefore, manufacturers, product/service providers are trying to study the mechanism of influence of sensory factors on human behavior to apply in marketing activities. That's why sensory marketing emerges. It closely links to the emotion and thoughts of customers, providing a great experience, thereby attracting and retaining them (Esther and Ángel, 2017).

Sensory marketing with a combination of sensory stimuli will bring customers diverse experiences, and generate a multidimensional perception of that product/service. Thus, sensory marketing can be applied in many different fields, especially in the field of health care - medical services. The study about sensory stimuli, mechanism impact of senses on behavior, and its implication to improve service quality and patient perception is really necessary.

Currently, medical service is not only considered as a medical examination and treatment activity, but it is also a process of patient (customer) experience with the hospital (brand). During the service experience, each "sensory touch" of the patient will create their different feelings, just a few "touchpoints" are enough to make customers switch from positive to negative perception. Therefore, focusing on improving service quality at each sensory touchpoint to improve the patient's perception and enhance the hospital's brand value is considered the main goal of hospitals today.

At present, sensory marketing is still a new concept that has not been fully exploited and analyzed. Although there have been some studies on sensory marketing, these studies often focus on business services such as hotels, restaurants, cafes, etc (Satti et al, 2019; Jang \& Lee, 2019; Kim et al, 2020), and not many studies on sensory marketing in health services. Among those few studies, there are relatively few studies that address the effects of all five senses (Marta Ugolini et al, 2014); most studies only focus on a few key factors such as sight, smell; and there has not been a thorough comparison between the senses.

In Vietnam, there have only been a few studies on sensory marketing. Besides, studies on perceived health service quality and satisfaction of Vietnamese hospitals mainly use the SERVPERF model of Cronin and Taylor (1992) as a theoretical foundation (Nhat, 2015; Ly \& Dung, 2016; Thanh, 2020).

With the desire to use a new marketing approach, this study uses the perspective of the patient and the patient's family to measure the influence of sensory variables on the patient's perception. From there, the authors will propose solutions to improve customer perception and to enhance customers' positive experience based on effective use of Sensory marketing elements.

\section{Literature review}

\subsection{Service Quality}

Services are produced and consumed with the direct participation of service beneficiaries and service providers 
(Surprenant and Solomon, 1987). This makes a service different from other tangible products thanks to its characteristics: intangibility, inseparability between service providers and users, heterogeneity in quality, perishability, and non-transferability of ownership.

Service Quality is the ability of service providers to satisfy the needs and expectations of customers (Parasuraman et al., 1988) is the "gap" between customer expectations and the actual results they receive (Woodside et al., 1989). Expectations form service quality based on the ideals and preeminent things that customers want the business to provide in three aspects: core services/product; service environment; service provision activities. Oliver (1993) argues that service providers need to continuously examine and evaluate these three aspects in order to ensure quality for customers.

\subsection{Perceived Service Quality}

Parasuraman et al. (1988) define perceived service quality as the consumer's assessment of the firm's distinctiveness. Customers often evaluate service quality based on the correlation between the service performance received and their expectations. These assessments are not based on service attributes, but rather on customers' emotions or memories (Jiang and Wang, 2006). Thus, customers judge perceived service quality based on how satisfied they feel with a service.

Researchers suggest that perceived service quality does not require the customer to experience the brand or the supplier (Oliver, 1993). Specifically, customers can perceive good service quality even if they have never experienced service at that restaurant. Accordingly, Oliver (1993) believes that customers can give their impressions of restaurant service quality based on personal opinions, regardless of whether they have ever "visited" that 5-star restaurant or not. This depends on the type of service as well as the brand segment of that service provider.

\subsection{Sensory Marketing}

The concept of Sensory Marketing was first defined by Schmitt (1999). Later, Krishna (2012) provided a more comprehensive definition of sensory marketing is a strategy that affects not only the consumer's five senses but also exerts a continuing influence on their emotions, perceptions, judgments, and behaviors. The American Marketing Association then also defines "Sensory marketing is marketing activities aimed at persuading customers by influencing their feelings and behavior".

As all five human senses are activated by marketing stimuli, business is able to get closer and deeper into the minds and hearts of customers strategically, to provide a multi-sensory experience. The brand then will have a long-term presence in the perception of the individual, gradually establishing an emotional connection with them (Hultén, Broweus and Dijk, 2009). In particular, thanks to the experience established by sensory stimuli, the company can create an imprint in the customer's perception, make customers recognize or even remember the brand after the emotional expressions that the brand leaves. Thus, the relationship between the brand and the customer will not end at mere communication and interaction but will be exploited more deeply in terms of sensory and emotional connections. This means that sensory marketing with strategic direction will demonstrate core values and brand identity with the combination of all five original senses, contributing to increasing satisfaction.

Sensory Marketing goes one step further with the aim to create a memorable experience related to all five senses and ultimately delivers a successful multi-sensory perception to customers. Since then, the brand has become a "soul", able to evoke emotions, exchange values with customers in an intimate way. The brand will be treated as a partner that could connect with customers on a deeper level, exhibit human-like attributes, have heart, mind, feelings, and reason (Hultén, Broweus and Dijk, 2009). Hultén, Broweus and Dijk (2009) also believe that it is only through a sensory experience that the final customer will have an accurate perception of the service, whether this is a simple sale transaction or a relationship between the brand and the customer is established.

\subsection{The relationship between Sensory Marketing and Perceived Service Quality}

As presented, five factors of multi-sensory experience have an impact on customers' perception of service quality. In the medical field, this is a type of highly specialized service that is very specific and different from other services. Through sensory touchpoints, human perception can be formed when experiencing the brand (Krishna, 2012). All five senses are active and play an important role in enhancing the experience and promoting positive perceptions of the quality of the medical services (Marta Ugolini et al., 2014). Therefore, the authors inherit and rely on the findings from the research gap to develop the following research model: 


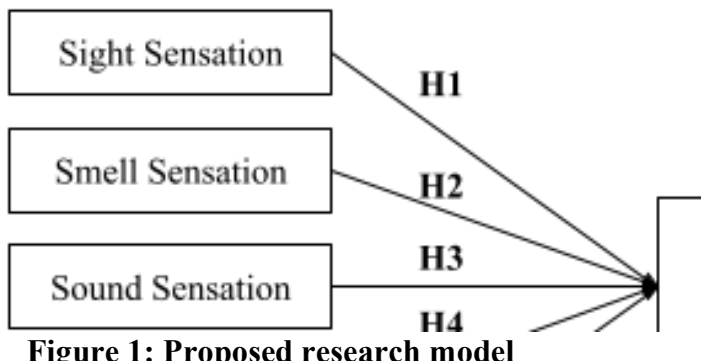

Figure 1: Proposed research model

The sensory sensation - five independent variables and dependent variables on perceived service quality are all measured by scales, through measuring the respondents' increasing agreement level from 1 to 5 (using a Likert scale). With that model, the following hypotheses are proposed:

H1: Sight sensation has an impact on customers' perceived service quality.

H2: Smell sensation has an impact on customers' perceived service quality.

H3: Sound sensation has an impact on customers' perceived service quality.

H4: Tactile sensation has an impact on customers' perceived service quality.

H5: Taste sensation has an impact on customers' perceived service quality.

\section{Methodology}

Based on theory and overview of research works, the authors build a research model and draft scale. The authors have synthesized, selected, and referenced the studies of Davies et al (2003); Mavrommatis et al (2011); Marta Ugolini et al (2014); Alahakoon \& Randiwela (2017); Zhao et al (2019); Jang and Lee (2019); Chua et al (2018); Kim et al (2020) to build the scale for the independent variable and the study of Kumar et al (2013); Tam (2004); Lee et al (2000) to build a scale for the dependent variable. Simultaneously, the authors edited and supplemented the scale from the results of in-depth interviews with participants who have experienced public medical services to ensure its suitability with actual conditions in Vietnam.

The qualitative research was conducted through in-depth interviews with 20 people who have experienced medical services at public hospitals to complete the variable measurement scales in the research model and build a preliminary quantitative questionnaire. the set. Preliminary quantitative research was conducted with 113 survey respondents. The results of the preliminary survey were used to check the suitability of the variables and measurement scales in the study through Cronbach Alpha reliability coefficient analysis and EFA analysis. The scale of measuring variables in the research model has been adjusted to be more appropriate and logical.

Data is collected through online and offline surveys. The survey questionnaire consists of three main parts. The first part includes questions about the customer's experience of using the medical service. The second part includes questions to collect customer assessments of the quality of public medical services on a Likert scale from 1 to 5 ( 1 - "strongly disagree" and 5 - "strongly agree") with 36 observed variables. The last part is the survey respondents' demographic information (age, gender, region, city, occupation, and income level) of survey participants. Its reliability has been confirmed by Cronbach's alpha coefficient.

Official quantitative research was carried out with a convenient non-probability sampling method and collected 619 survey questionnaires. The research subjects are Vietnamese people aged 18-65 years old, including patients and their family members, who have experienced medical services at public health facilities across the country. In which, the number of participants in the age group of 18-25, 26-40, 41-55, 56-65 years old accounted for $29.1 \% ; 31.7 \% ; 26.8 \%$, and $12.4 \%$, respectively. Besides, $73.2 \%$ of survey respondents are living in urban areas. Most of the medical service experience at public hospitals is assessed from the patient's perspective $(63.8 \%)$. In addition, $43.6 \%$ of customers have chosen general hospitals to experience medical services and $13,9 \%$ of people have ever visited a specialist hospital. The number of people choosing both types of hospitals at the same time accounted for $42.5 \%$. In addition, the majority of survey participants always use health insurance (accounting for 40.7\%). Besides, 44.4\% have used both forms of non - health insurance and health insurance. Only $14.9 \%$ of people have always used non - health insurance at public health facilities.

The final results obtained were coded and the scale was tested using SPSS 26 and AMOS 20. In which, the Compare means analysis, the Cronbach Alpha reliability analysis, the confirmatory factor (CFA), check the suitability of the model, test the hypothesis, evaluate the impact relationship through the SEM model used in this study. 


\section{Research results}

4.1. Evaluation of the influence of marketing on customer's perceived quality of public health services 4.1.1. Measuring the reliability of Cronbach's Alpha scale

Cronbach's Alpha is used to assess the reliability of the scale (Table 1) through the official quantitative survey sample. The results show that all the value scales of the factor groups are reliable and the data correlation is consistent with the scales (the overall index of all variables in the model reached 0.893 ).

Table 1. Cronbach's Alpha analysis result

\begin{tabular}{cccc}
\hline Factor & Cronbach's Alpha & $\begin{array}{c}\text { Corrected Item- } \\
\text { Total Correlation }\end{array}$ & $\begin{array}{c}\text { Number of scales } \\
\text { eliminated }\end{array}$ \\
\hline SIGHT (SI) & 0,918 & $0,621-0,752$ & $0 / 9$ \\
SOUND (SO) & 0,859 & $0,636-0,722$ & $0 / 5$ \\
SMELL (SM) & 0,907 & $0,734-0,798$ & $0 / 5$ \\
TACTILE (TAC) & 0,851 & $0,600-0,747$ & $0 / 5$ \\
TASTE (TAS) & 0,923 & $0,644-0,830$ & $0 / 6$ \\
PERCEIVED SERVICE & 0,904 & $0,866-0,871$ & $0 / 4$ \\
QUALITY (PSQ) & & 0,806 & 0 \\
\hline
\end{tabular}

Source: Summary of the authors' results, 2021

\subsubsection{Confirmatory factor analysis (CFA)}

CFA analysis was used to assess the research model fit. The results show that the scales of measuring independent variables have converged on 5 sensory factors including SIGHT, SOUND, SMELL, TACTILE, TASTE.

The authors reviewed the standardized residual covariances to improve the Model Fit indexes to the best standard. Since then, the authors have removed some scales: SO2, SO3, SM3, TAS1, and PSQ3. Thus, the Model Fit indexes show that the research model is completely built appropriately.

Table 2: Model Fit Index

\begin{tabular}{ccc}
\hline & Index & Evaluation \\
\hline CMIN/DF & 4,250 & Acceptable $(<5)$ \\
GFI & 0,868 & Acceptable $(>0,8)$ \\
CFI & 0,929 & Acceptable $(>0,9)$ \\
RMSEA & 0,073 & Acceptable $(<0,08)$ \\
\hline
\end{tabular}

Source: Summary of the authors' results, 2021

Confirmatory factor analysis not only evaluates Model Fit but also considers convergent validity and discriminant validity among variables. According to Hair et al. (2010), during the Validity test, the authors gradually eliminated observed variables with low-reliability coefficients (SI9, SO1, TAC1, TAC4). Simultaneously, the authors separated a group of scales combined from the scales of SIGHT and SOUND variables, including "The doctor's gestures and eyes is very friendly" (SI7); "The attitude and manner of the medical staff are considerate and attentive" (SI8); "The voice of medical staff is clear and easy to understand" (SO4); "The volume of the medical staff's voice is audible enough" (SO5). The results are shown in Table 4:

(1) The AVE index $>0.5$ in all variables ensures Convergent Validity.

(2) The index $M S V<A V E$ and Square Root of $A V E>$ Correlation in all variables also ensures discriminant Validity.

Table 3: Model Validity Measures

\begin{tabular}{|c|c|c|c|c|c|c|c|c|c|c|}
\hline & CR & AVE & MSV & $\operatorname{Max} R(H)$ & TASTE & SIGHT & SMELL & SISO & TACTILE & PSQ \\
\hline TASTE & 0,906 & 0,661 & 0,521 & 0,916 & 0,813 & & & & & \\
\hline SIGHT & 0,897 & 0,593 & 0,518 & 0,9 & $0,667 * * *$ & 0,77 & & & & \\
\hline SMELL & 0,886 & 0,66 & 0,609 & 0,888 & $0,722 * * *$ & $0,704 * * *$ & 0,812 & & & \\
\hline SISO & 0,893 & 0,678 & 0,537 & 0,911 & $0,590 * * *$ & $0,660 * * *$ & $0,660 * * *$ & 0,823 & & \\
\hline TACTILE & 0,809 & 0,588 & 0,562 & 0,827 & $0,548 * * *$ & $0,651 * * *$ & $0,737 * * *$ & $0,733 * * *$ & 0,767 & \\
\hline PSQ & 0,871 & 0,692 & 0,609 & 0,872 & $0,682 * * *$ & $0,720 * * *$ & $0,781 * * *$ & $0,641 * * *$ & $0,750 * * *$ & $\mathbf{0 , 8 3 2}$ \\
\hline
\end{tabular}

Thus, the CFA results have proved that the proposed research model is completely consistent with the theory. The measurement scales for the SIGHT, TACTILE, SMELL, TASTE, PSQ variables have a strong relationship with each other and can explain well for each representative variable. The authors continue using the results of CFA analysis to test the hypothesis and evaluate the relationship between sensory stimuli and perceived service quality. For the latent variable (SISO) combined from the scales of SIGHT and SOUND, the authors have not determined whether this variable represents a certain sense in the Sensory Marketing research 
model. However, the authors still put this latent variable into the hypothesis test $(\boldsymbol{H} 2 \boldsymbol{a})$ and evaluate its impact relationship with the dependent variable. On that basis, the authors will make specific conclusions about this latent variable.

\subsubsection{Structural Equation Modeling analysis}

To analyze the multidimensional relationship between the dependent variable "Perceived service quality" (PSQ) and independent variables in the model, the authors used the Structural Equation Modeling technique. The obtained results are shown in Figure 2:

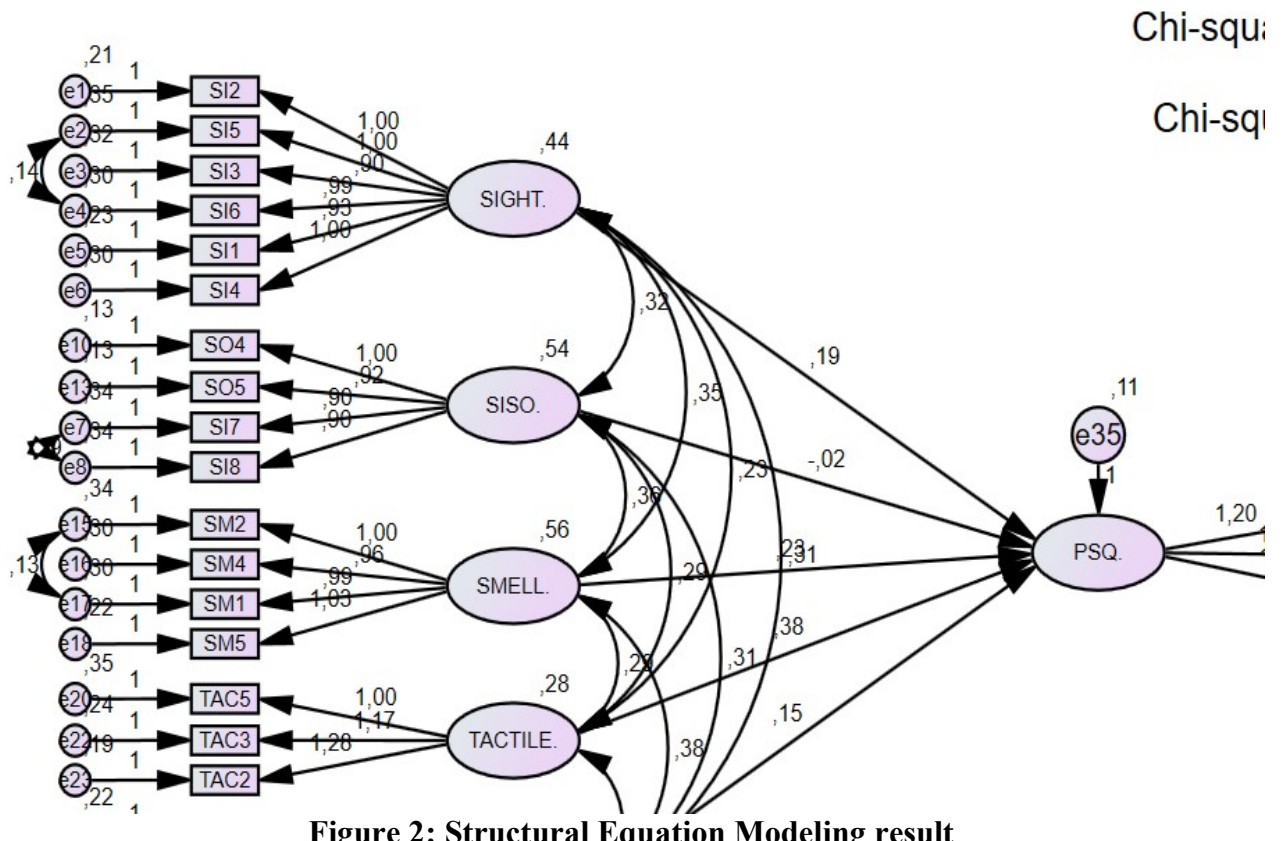

Figure 2: Structural Equation Modeling result

Source: Summary of the authors' results, 2021

It can be seen that sensory factors affect people's satisfaction when using health services. The independent variables explained $71.9 \%$ of the change of the dependent variable, the rest $28.1 \%$ was contributed by factors outside the model and random errors. This shows that the influence of sensory factors on customers' perceived health services quality in the research context is very large.

The $\mathrm{P}$ index (sig) of the variables are all $<0.05$, reaching the $95 \%$ confidence level, so the relationships between the independent variables and the dependent variable are significant. However, with a P-value $=0.572$, hypothesis $\boldsymbol{H} \mathbf{2} \boldsymbol{a}$ will be rejected. Therefore, the SEM results only accept the proposed hypotheses $\boldsymbol{H 1}, \boldsymbol{H} 3, \boldsymbol{H} 4$, and $\boldsymbol{H 5}$.

\begin{tabular}{ccccc}
\multicolumn{5}{c}{ Table 4: Summary of SEM results } \\
\hline $\begin{array}{c}\text { Hypothesis } \\
\text { (Hs) }\end{array}$ & Unstandardized Estimate & $\begin{array}{c}\text { P-Value } \\
\text { (Sig) }\end{array}$ & Evaluation \\
\hline H1 & PSQ <--- SIGHT & 0,193 & $* * *$ & Accept \\
H2a & PSQ <--- SISO & $-0,025$ & 0,572 & Reject \\
H4 & PSQ <--- SMELL & 0,233 & $* * *$ & Accept \\
H5 & PSQ <--- TACTILE & 0,383 & $* * *$ & Accept \\
H6 & PSQ <--- TASTE & 0,150 & $* * *$ & Accept \\
\hline
\end{tabular}

Source: Summary of the authors' results, 2021

Research results show that Tactile Sensation (TACTILE) and Smell Sensation (SMELL) are the two factors that have the strongest impact on the perceived service quality (PSQ). The third is Sight Sensation (SIGHT) and lastly, Taste Sensation (TASTE) has the least influence on the dependent variable. The latent variable (SISO) has no impact on the perceived service quality.

Tactile Sensation (TACTILE) plays the most important role, greatly influencing the perceived quality of people using public hospitals' medical services with an impact level of $38.3 \%$. This result is consistent with the studies of Alahakoon and Randiwela (2017), Marta Ugolini et al (2014). These studies address tactile stimuli such as air, temperature, convenience when moving in the hospital and the interactions of medical staff during treatment. 
Smell Sensation (SMELL) has the second strongest level on the dependent variable (23.3\%). This means that if patients have a positive perception of the olfactory impact factors, they will also have a good perception of the hospital service quality during the experience process. These olfactory stimuli are expressed through the scent of the ward, the smell of disinfectant, the smell of food, or the smell of the restroom (Marta Ugolini et al., 2014; Zhao et al., 2019; Jang and Lee, 2019; Kim et al., 2020).

Sight Sensation (SIGHT) has the ability to change people's perceived public health services quality, reaching $19.3 \%$. When people come to the hospital, they probably pay attention to the paint color of the wall, the lighting, the facilities, and the hospital campus. More specifically, if the customer finds that the facilities of the public hospital are very comfortable and modern; the hospital campus is airy and clean, they will have a better perception of the public hospital's service quality.

Taste Sensation (TASTE) is the factor that has the least impact but also affects $15 \%$ on the change in patients perceived medical services quality. This can be explained because when people come to the public hospital, they mainly pay attention to medical examination and the hospital environment, so eating is not their most concern.

The latent variable (SISO), which is combined from the scale of two variables "SIGHT" and "SOUND", has no impact on the dependent variable. Although it is not possible to determine which sense is represented by this latent variable in the research model of Sensory Marketing, the authors found that SI7, SI8, SO4, SO5 are the scales related to the perception of medical staff who directly treat and interact with patients throughout the medical examination process. Therefore, the authors will continue to study and analyze this factor more deeply based on the patient's assessment through measurement judgments.

Figure 3: Comparing customer perceptions about medical staff in different age groups

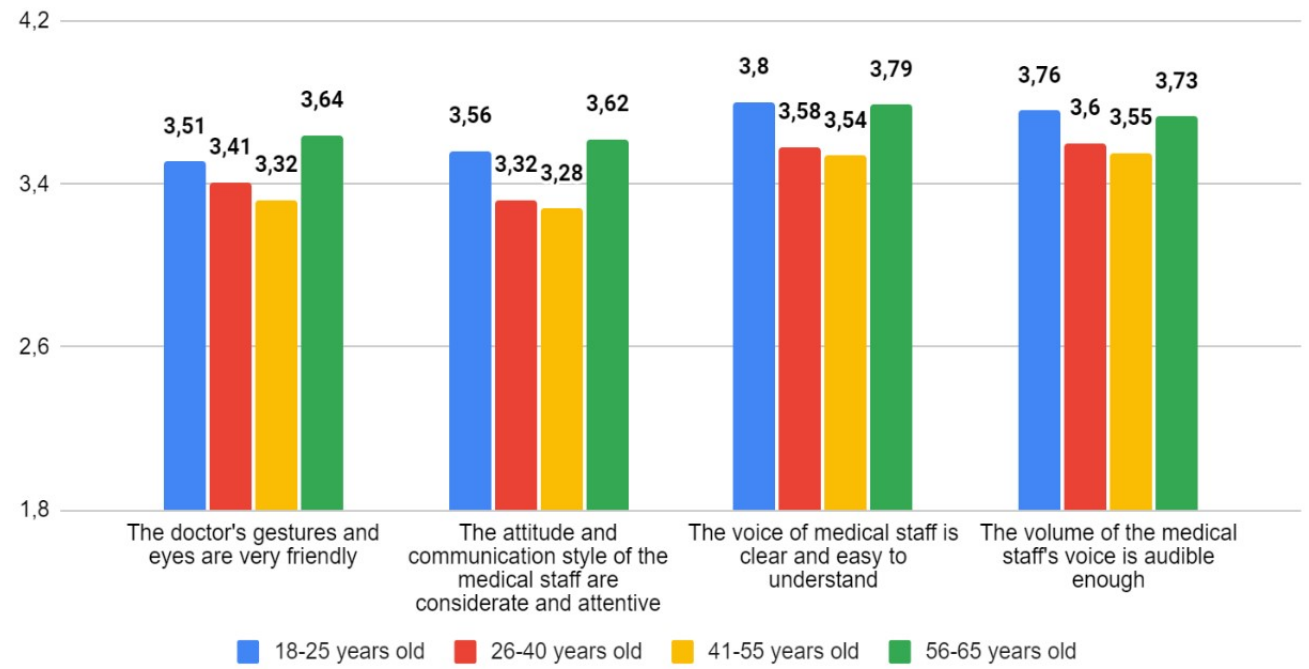

Source: Summary of the authors' results, 2021

When evaluating medical staff in public hospitals, two age groups 18-25 and 56-65 all had a good perception of "gestures", "manner" as well as "voice" and "voice volume" of doctors and nurses with average scores ranging from Agree. They feel the friendliness and thoughtfulness from the medical staff at the public hospital. Meanwhile, the two groups of 26-40 and 41-55 years old did not appreciate the above criteria of health workers in public hospitals with the average score at a neutral level (ranging from 3.28 to 3,32) and above neutral (3.41). Therefore, it has also affected the perceived medical services quality of group 41 - 55 years old with the lowest average score of 3.15. Therefore, public hospitals need to focus on improving the perceived service quality among customers, especially those who are in the age group of $26-40$ and 41 - 55 by improving the attitude and level of care of medical staff. These may also be the two groups of customers who experience the most medical services at public hospitals.

Thus, although the latent variable (SISO) does not represent any sense in the Sensory Marketing research model, the authors believe that it can also be one of the factors that bring a positive experience for customers when using public medical service.

\subsection{Customer's perceived service quality of Vietnamese public hospitals}

The authors continue finding the current assessment among customers in terms of perceived medical service quality to build scientific recommendations on whether to enhance or improve for public hospitals in Vietnam by using compare means statistic. When analyzing the comparison (Figure 4), the authors found a positive trend in the assessment of customers' perceived service quality with different expectations levels. The more customers 
expect the service, the more likely they are to have a good assessment of the quality of public health services. Specifically, with the group of customers who have no expectation, they rate the public medical service quality with an average score of 2,41 - 2,86 (disagree). Meanwhile, customers with high expectations appreciate the quality of Vietnamese public medical services with an average score of 3,32 - 3,7 (agreement). Thus, public hospitals need to focus on improving service quality further to increase expectations, thereby improving customer perception.

$$
4,20
$$

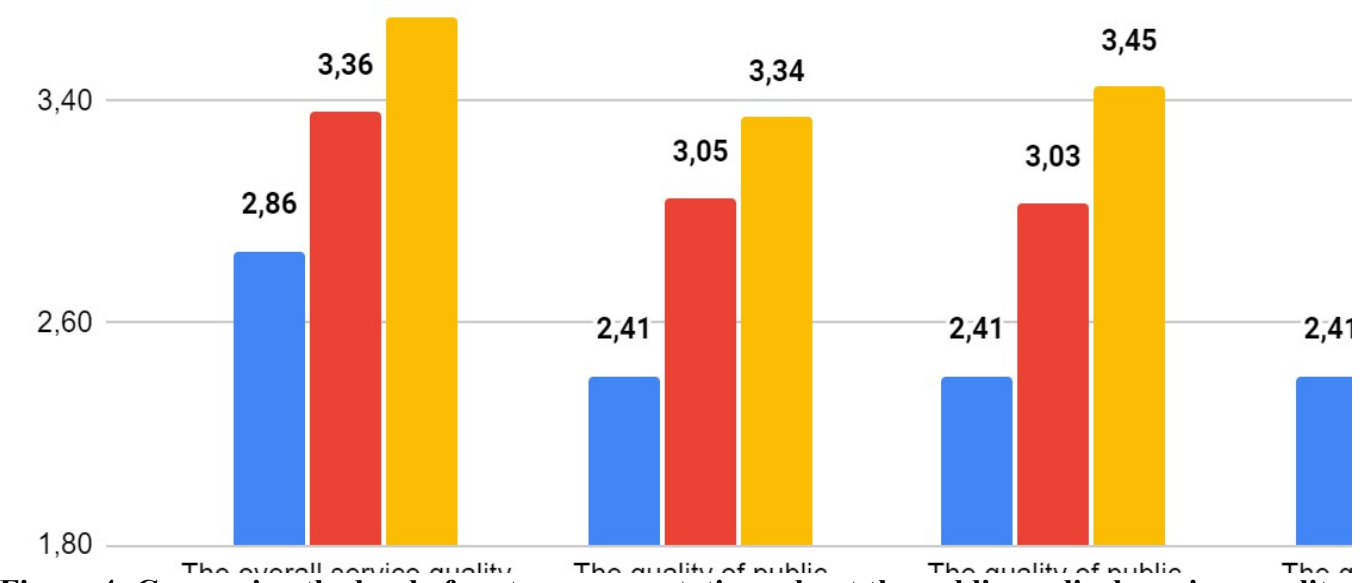

Figure 4: Comparing the level of customer expectations about the public medical services quality

Source: Summary of the authors' results, 2021

\section{Conclusions and recommendations}

5.1. Multi-sensory experience plays an important role in enhancing customer's perception of the medical services quality in public hospitals

Research results have confirmed that sensory stimuli according to Sensory Marketing theory have a great influence on people's positive perception of public health services with the $r$ square index up to $71.9 \%$. The tactile stimuli dominate the most, followed by the olfactory, visual, and finally taste stimuli. This result shows the extremely important role of multi-sensory experience in improving and enhancing the perceived health service quality of patients in public hospitals. The results have reinforced the solid theory of Sensory Marketing thanks to the research model, which is often applied in common types of services, now can be applied to the healthcare service.

In addition, a potential factor discovered outside the model, showing the characteristics of medical staff (based on demeanor, gestures, voice), should also be noticed and concerned by administrators.

\subsection{Recommendations}

Based on the research results, the measurement criteria for each sense sensation explain their meaning well, helping the authors to have a basis for proposing practical recommendations to improve the perceived service quality of the people. Hospital administrators and operators need to build a multi-sensory experience, in which the most focus is on the following tactile, olfactory, visual, and taste stimuli.

\section{Exploiting the tactile element:}

(1) Hospitals need to pay attention to the temperature in hospital waiting rooms, clinics, and inpatient rooms. The right temperature will directly bring positive feelings to the patient, then avoid uncomfortably and suffocate feelings for people while waiting for the examination. Hospitals need to regularly repair and promptly replace the damaged fans and air conditioners; maintain devices periodically to ensure their cooling and heating ability.

(2) The floor must ensure safety for everyone during the movement, avoid wet floors that are easy to slip, but still ensure hygiene. Also, it is necessary to regularly check and repair areas with worn, cracked tile floors, potentially dangerous for patients.

(3) Doctors and nurses should have a gentle and proper operation; provide physical therapy and massage to minimize pain and discomfort during the diagnosis and treatment process; show professionalism and empathy for the patient. Supporting mental reassurance would help patients reduce feelings of anxiety, stress, and fear during the medical examination and treatment. 


\section{Exploiting the olfactory element:}

(1) Deodorize the restroom by using a light scent or room fragrance. Besides, it is necessary to improve the ventilation facilities to avoid the smell of disinfectant in the air for a long time, causing discomfort and stress for patients.

(2) Pay attention to handling scents that affect the patient's direct living space: uniform and room smell, body odor,... with a view to enhancing the positive perception of the service by using deodorizer or daily spraying room deodorizers.

\section{Exploiting visual elements:}

(1) Focus on investing in hospital facilities to create a positive feeling for the patient from the first touchpoint with the service.

(2) Optimizing space visually by investing in the interior and exterior layout of the hospital, to not only create a welcoming feeling for patients but also to avoid the crowded and cramped situations in the hospital campus.

(3) Use a variety of wall paint tones to create a welcome space instead of using only one tone, which can lead to a strange feeling in the hospital among patients. Combine several warm and cold tones harmoniously to suit people's tastes when it comes to wall-painting color. Warm lights should be added in public areas like waiting rooms, reception halls to be more visually effective for service users.

\section{Exploiting the taste factor:}

Providing delicious and nutritious food will not only reduce the risk of diseases from outside but also contribute to improving the ability to recover after treatment in the hospital. The hospital menu needs to be more diversified, processed cleanly, and limited in oil and grease to ensure the freshness of the dishes when provided to patients. Establish the standards of care and service to the people, ensure that patients have a good experience in terms of taste, and improve the quality of medical services.

\subsection{Limitations and directions for future research}

Firstly, the structure of the sample is not diverse in terms of geographical area. The author collects research samples mainly in urban areas (including mainly Hanoi and some major cities and provinces across the country), in addition, there are respondents in rural areas, however, this proportion is quite small.

Second, although this study focuses on studying the vital role of sensory experience on the perceived service quality, auditory stimuli have not yet been clarified. This may also be a research gap for the authors to expand research further in the future.

Since this is the first study on sensory marketing in the medical field in Vietnam, the research limitation still exists, the authors have difficulty in referencing and collecting data. In the context of the Covid-19 epidemic, the authors do not have enough time and space to collect and analyze diverse information from many areas easily. Therefore, more studies are needed to further dig into the research problem.

\section{Reference}

Alahakoon, S., \& Randiwela, P. (2017). Sensory Marketing and Healthcare Service in Sri Lanka. Cambridge Business and Economics Conference, $4,74$. https://scholar.google.com/citations?view_op=view_citation\&hl=en\&user=aQhyDoAAAAJ\&citation_for_view=-aQhyDoAAAAJ:u5HHmVD_uO8C

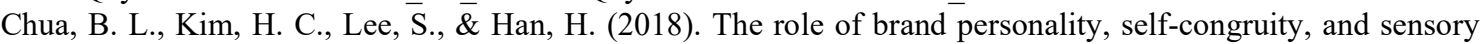 experience in elucidating sky lounge users' behavior. Journal of Travel \& Tourism Marketing, 36(1), 2942. https://doi.org/10.1080/10548408.2018.1488650

Cronin, J. J., \& Taylor, S. A. (1992). Measuring Service Quality: A Reexamination and Extension. Journal of Marketing, 56(3), 55. https://doi.org/10.2307/1252296

Davies, B. J., Kooijmanb, D., \& Warda, P. (2003). The Sweet Smell of Success: Olfaction in Retailing. Journal of Marketing Management, 19(5), 611-627. https://doi.org/10.1362/026725703322189977

Esther, S. N., \& Ángel, A. C. B. (2017). Sensory and Aroma Marketing. Wageningen Academic Pub.

Hultén, B., Broweus, N., Dijk, V. M., \& Dijk, V. M. (2009). Sensory Marketing (2009th ed.). Palgrave Macmillan.

Jang, H. W., \& Lee, S. B. (2019). Applying Effective Sensory Marketing to Sustainable Coffee Shop Business Management. Sustainability, 11(22), 6430. https://doi.org/10.3390/su11226430

Jiang, Y., \& Wang, L.C. (2006). The impact of affect on service quality and satisfaction: the moderation of service contexts. Journal of Services Marketing, 20(4), 211-218. https://doi.org/10.1108/08876040610674562

Kim, W. H., Lee, S. H., \& Kim, K. S. (2020). Effects of sensory marketing on customer satisfaction and revisit intention in the hotel industry: the moderating roles of customers' prior experience and gender. Anatolia, 31(4), 523-535. https://doi.org/10.1080/13032917.2020.1783692

Kumar, P. (2013). Multisensory Marketing: Creating New Sustainability Perspective in Hospitality Sector. Atna 
- Journal of Tourism Studies, 8(1), 43-55. https://doi.org/10.12727/ajts.9.4

Krishna, A. (2012). An integrative review of sensory marketing: Engaging the senses to affect perception, judgment and behavior. Journal of Consumer Psychology, 22(3), 332-351. https://doi.org/10.1016/j.jcps.2011.08.003

Lee, H., Lee, Y., \& Yoo, D. (2000). The determinants of perceived service quality and its relationship with satisfaction. Journal of Services Marketing, 14(3), 217-231. https://doi.org/10.1108/08876040010327220

Ly, P. N. K. D., \& Dung, L. T. (2016). Relationship between service quality and satisfaction of citizens for health examination and treatment services: A case study in Ho Chi Minh city. Journal of Science of Lac Hong University, 5, 47-52. https://hu.edu.vn/Data/News/383/files/09_Tien_Dung_Dan_Ly.pdf

Marta Ugolini, M., Rossato, C., \& Baccarani, C. (2014). A five-senses perspective to quality in hospitals. The TQM Journal, 26(3), 284-299. https://doi.org/10.1108/tqm-01-2014-0010

Mavrommatis, Y., Moynihan, P. J., Gosney, M. A., \& Methven, L. (2011). Hospital catering systems and their impact on the sensorial profile of foods provided to older patients in the UK. Appetite, 57(1), 14-20. https://doi.org/10.1016/j.appet.2011.03.010

Nhat, H. B. (2015). Satisfaction of inpatients with the quality of medical examination and treatment services of hospitals in Long Xuyen City. Journal of Science, 6, 111-119.

Oliver, R. L., \& Rust, R. T. (1993). Service Quality: New Directions in Theory and Practice. Google Books. Retrieved 2021,

from https://books.google.com.vn/books?hl=vi\&lr=\&id=c3woDAAAQBAJ\&oi=fnd\&pg=PT7\&dq=Oliver,+Rich ard+L.+(1993)\&ots=zqZbxcuQLs\&sig=KgdfX0dQO46m1AI6jQ5XYzmN6M\&redir_esc=y\#v=onepage\&q=Oliver\%2C\%20Richard\%20L.\%20(1993)\&f=f alse

Parasuraman, A., Zeithaml, Valerie A. \& Berry, Leonard L. (1988) "SERVQUAL: a multiple-item scale for measuring consumer perceptions of service quality," Journal of Retailing, vol. 64(1), p. 12-40

Satti, Z. W., Babar, S. F., \& Ahmad, H. M. (2019). Exploring mediating role of service quality in the association between sensory marketing and customer satisfaction. Total Quality Management \& Business Excellence, 32(7-8), 719-736. https://doi.org/10.1080/14783363.2019.1632185

Schmitt, B. (1999). Experiential Marketing. Journal of Marketing Management, 15(1-3), 53-67. https://doi.org/10.1362/026725799784870496

Surprenant, C. F., \& Solomon, M. R. (1987). Predictability and Personalization in the Service Encounter. Journal of Marketing, 51(2), 86-96. https://doi.org/10.1177/002224298705100207

Tam, J. L. (2004). Customer Satisfaction, Service Quality and Perceived Value: An Integrative Model. Journal of Marketing Management, 20(7-8), 897-917. https://doi.org/10.1362/0267257041838719

Thanh, N. T. (2020). Sự hài lòng của bệnh nhân, người nhà trong quá trình khám chữa bệnh tại bệnh viện công lập Hà Nội. Tạp chí Tài chính Doanh nghiệp. Retrieved 2021, from https://taichinhdoanhnghiep.net.vn/suhai-long-cua-benh-nhan-nguoi-nha-trong-qua-trinh-kham-chua-benh-tai-benh-vien-cong-lap-ha-noid13381.html

Woodside, A. G., Frey, L. L., \& Daly, R. T. (1989). Linking service quality, customer satisfaction, and behavioral intention. Journal of Health Care Marketing, 9(4), 5-17.

Zhao, J. B., Wang, Y. L., Ma, Q. W., Zhao, J. B., Zhang, X. Y., \& Zou, L. Q. (2019). The Chemosensory Pleasure Scale: A New Assessment for Measuring Hedonic Smell and Taste Capacities. Chemical Senses, 44(7), 457-464. https://doi.org/10.1093/chemse/bjz040 